\title{
Plant Genotype Shapes Ant-Aphid Interactions: Implications for Community Structure and Indirect Plant Defense
}

\author{
Kailen A. Mooney ${ }^{1,2, *}$ and Anurag A. Agrawal ${ }^{2, \dagger}$ \\ 1. Department of Ecology and Evolutionary Biology, University of \\ California, Irvine, California 92697; \\ 2. Department of Ecology and Evolutionary Biology, Cornell \\ University, Ithaca, New York 14853
}

Submitted May 28, 2007; Accepted December 17, 2007;

Electronically published April 15, 2008

\begin{abstract}
AвSTRACT: Little is known about the mechanisms by which plant genotype shapes arthropod community structure. In a field experiment, we measured the effects of milkweed (Asclepias syriaca) genotype and ants on milkweed arthropods. Populations of the anttended aphid Aphis asclepiadis and the untended aphid Myzocallis asclepiadis varied eight- to 18 -fold among milkweed genotypes, depending on aphid species and whether ants were present. There was no milkweed effect on predatory arthropods. Ants increased Aphis abundance 59\%, decreased Myzocallis abundance 52\%, and decreased predator abundance $56 \%$. Milkweed genotype indirectly influenced ants via direct effects on Aphis and Myzocallis abundance. Milkweed genotype also modified ant-aphid interactions, influencing the number of ants attracted per Aphis and Myzocallis. While ant effects on Myzocallis were consistently negative, effects on Aphis ranged from antagonistic to mutualistic among milkweed genotypes. As a consequence of milkweed effects on ant-aphid interactions, ant abundance varied 13-fold among milkweed genotypes, and monarch caterpillar survival was negatively correlated with genetic variation in ant abundance. We speculate that heritable variation in milkweed phloem sap drives these effects on aphids, ants, and caterpillars. In summary, milkweed exerts genetic control over the interactions between aphids and an ant that provides defense against foliage-feeding caterpillars.
\end{abstract}

Keywords: ant-aphid mutualism, indirect defense, plant genetic effects, community ecology.

Evidence has begun to build for the importance of plant genotype in structuring higher levels of ecological orga-

* Corresponding author; e-mail: mooneyk@tritrophic.org.

† E-mail: aa337@cornell.edu.

Am. Nat. 2008. Vol. 171, pp. E195-E205. (c) 2008 by The University of Chicago. 0003-0147/2008/17106-42631\$15.00. All rights reserved. DOI: $10.1086 / 587758$ nization, including whole arthropod communities (Maddox and Root 1990; Wimp and Whitham 2001; Johnson and Agrawal 2005; Crutsinger et al. 2006) and ecosystem function (Crutsinger et al. 2006; Madritch et al. 2006; Whitham et al. 2006). It has been known for decades that genetically based variation in plant phenotypes has important consequences for the preference and performance of individual herbivore species. In contrast, there is surprisingly little known about how plant genetic effects on individual species scale up to shape community structure.

There are two basic means by which plant genotype could influence higher trophic levels and community structure. First are the well-known direct effects of plant traits on individual species, which may in turn propagate through food webs as chains of direct interactions ("interaction chains" sensu Wootton 1994). Under this scenario, community structure differs among plant genotypes, but on a per capita basis the interactions among resident arthropod species remain unchanged. Second, plant traits may modify the form of the pairwise interactions among members of the arthropod community ("interaction modification" sensu Wootton 1994). Interaction chains and modifications constitute fundamentally different types of indirect interactions, and distinguishing between the two has evolutionary (Iwao and Rausher 1997; Strauss et al. 2005) and ecological (Abrams 1995; Peacor and Werner 2001; Preisser et al. 2005) consequences. For instance, whether plant genotype indirectly influences predator abundance through changes in herbivore abundance versus changes in predator-herbivore interactions (interaction chain and interaction modification, respectively) has implications for the outcome of coevolution among plants and resident arthropods (e.g., whether predators indirectly select for plant traits) and for community structure (e.g., the relative abundance of predators and herbivores). Thus, determining whether interaction chains or modifications link plant genotype to higher levels of ecological organization represents an important first step toward a mechanistic understanding of how community structure may be driven by the genetics of primary producers. 
Just as plant genotype can influence community structure from the bottom up, so too can community structure influence the growth and fitness of host plants from the top down. For example, Rudgers (2004) not only demonstrated heritable variation in wild cotton for traits influencing the abundance of nectar-feeding ants but also showed that genotypes with more ants had higher fitness because ants preyed on cotton's herbivores. This work revealed how plant genetic influence over community structure can loop back and affect plant fitness and evolution. However, it is still unclear under what circumstances such feedbacks are likely to occur. Studies on the feedback between plant genotype and community structure thus represent an important frontier between community and evolutionary ecology (Whitham et al. 2006; Johnson and Stinchcombe 2007).

Hemipteran-tending ants are present in most terrestrial communities, where they have wide-ranging effects on arthropod communities (Styrsky and Eubanks 2007). There is substantial evidence that heritable plant traits directly influence hemipteran performance (Fritz and Simms 1992). There is also evidence that such plant effects on hemipteran performance in turn have indirect effects on ant abundance (Vrieling et al. 1991; Wimp and Whitham 2001). We conducted a factorial field experiment in which we measured the effects of ants and common milkweed (Asclepias syriaca L.) genotype on arthropod community structure. We tested whether plant genotype indirectly influences ant abundance, not only through interaction chains - that is, by influencing hemipteran abundancebut also through interaction modification, by influencing ant-hemipteran interaction outcomes among plant genotypes. Furthermore, we investigated these dynamics for two ecologically distinct aphid species, only one of which is tended by ants.

This experiment addressed four specific questions: First, do the top-down effects of ants on milkweed arthropods differ among milkweed genotypes? Second, do milkweed genotypes vary in the number of ants that recruit to them, and are such effects direct, indirect due to changes in aphid abundance (interaction chains), or indirect due to plant modification of ant-aphid interactions (interaction modifications)? Third, how do such indirect effects of milkweed on ants differ when transmitted via untended versus tended aphid species? Finally, do aphid-recruited ants defend milkweed from nonaphid herbivores?

\section{Methods}

\section{Natural History}

The common milkweed (Asclepias syriaca) is a widespread, native perennial that occurs throughout eastern North
America. This study was conducted in an old field near Ithaca, NY, $\left(42^{\circ} 30^{\prime} 1.44^{\prime \prime} \mathrm{N}, 76^{\circ} 26^{\prime} 8.52^{\prime \prime} \mathrm{W}\right)$. At our study sites, milkweed is principally fed on by two aphid species, Aphis asclepiadis Fitch and Myzocallis asclepiadis (Monel), hereafter "Aphis" and "Myzocallis," respectively. The ant Formica podzolica (Francoeur) tends Aphis, while Myzocallis is not tended by F. podzolica or, to our knowledge, by any other ants. Seeds from a single fruit of $A$. syriaca are full siblings because of the pollinia pollination system of milkweed (i.e., a single pollen sac or pollinium sires all of the seeds from a flower; Gold and Shore 1995).

\section{Experimental Protocols}

In spring 2005, we germinated 10 milkweed seeds from each of 32 full-sib families (hereafter referred to as "families") collected from a single population approximately 5 $\mathrm{km}$ from our field site. In a common garden, we found significant or marginally significant full-sib heritabilities among these milkweed families in all traits measured: cardenolide concentration in leaves $\left(H^{2}=0.19, P<.05\right)$, specific leaf area $\left(H^{2}=0.23, P<.05\right)$, water percentage $\left(H^{2}=0.21, P<.05\right)$, latex production $\left(H^{2}=0.19, P<\right.$ $0.01)$, leaf toughness $\left(H^{2}=0.14, P=.07\right)$, and trichome density $\left(H^{2}=0.31, P<.01 ; \mathrm{K}\right.$. A. Mooney and A. A. Agrawal, unpublished data).

We initially grew plants in growth chambers with potting soil in $500-\mathrm{mL}$ pots that were watered as needed and fertilized weekly for 6 weeks. By growing all plants for this relatively long period under hospitable conditions, we minimized maternal effects on milkweed phenotypes (Rausher 1992). Past work with A. syriaca treated in this way showed that trait heritabilities measured in the year of and the year after plantings were similar, suggesting that most if not all variation associated with full-sib family is genetically based (Agrawal 2005). On June 26, we transplanted plants to the field, placing 16 plants each in $3-\mathrm{m}$ diameter circles around each of $20 \mathrm{~F}$. podzolica mounds. Our experimental design was a balanced incomplete block, with ant mound as the block and milkweed family and ant exclusion as experimental factors. The SAS procedure OPTEX (SAS Institute 2003) allowed us to assign experimental treatments to each of the 320 plant positions according to the requirements of the balanced incomplete block design. We excluded ants from half of these plants by burying $20-\mathrm{cm}$-tall by $25-\mathrm{cm}$-diameter aluminum flashing rings into the soil $5 \mathrm{~cm}$ deep and coating the outside surface with sticky paste (Tanglefoot, Grand Rapids, MI). We controlled for any untended effects of the aluminum rings by setting $15-\mathrm{cm}$-tall rings loosely on the ground around control plants to allow ant access.

We censused arthropods on July 14, July 25, August 2, August 16, and August 25, classifying each arthropod as 

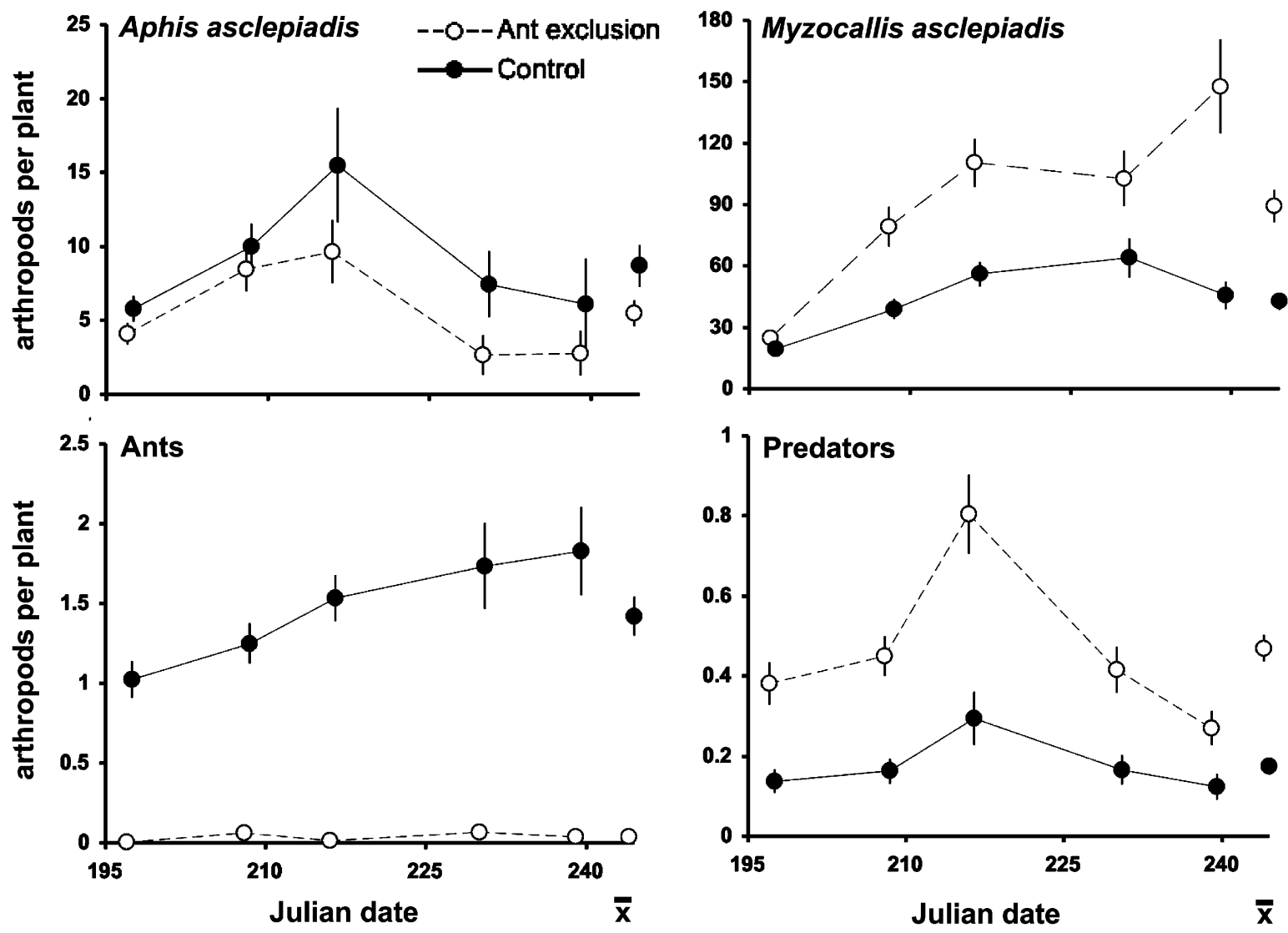

Figure 1: Arthropod abundance per plant $( \pm 1 \mathrm{SE})$ in ant exclusion and control treatments at four sampling dates. Season means are given on the right margin of each panel. The means reported here are raw means, whereas those reported elsewhere in the text and figures are least square means adjusted for variance among ant mounds and/or milkweed genetic families. Consequently, the magnitude of ant effects in season means shown here are similar to those reported in the text and figures, but the absolute values for arthropod abundance differ. Sample size per mean is 160 plants for the first sampling period but decreases over the growing season as a result of plant mortality (see "Methods" for details).

Aphis, Myzocallis, ant (all F. podzolica), or arthropod predator. Arthropod predators consisted of larval and adult ladybeetles (Coccindlidae: Coleoptera), larval syrphid flies (Syrphidae: Diptera), lacewing larvae (Chrysopidae: Neuroptera), predatory plant bugs (Miridae: Hemiptera), and spiders (Araneae). Herbivores other than the two aphid species were rare. These rather coarse taxonomic groupings (ants, Aphis, Myzocallis, predators) were necessary because no other species or guilds of arthropod were sufficiently abundant for analysis. Finally, we performed a bioassay to assess the influence of ants and milkweed family on other herbivores by placing a single neonate monarch caterpillar (Danaus plexippus [L.]) on each plant on August 15 and monitoring their survival (presence, absence) after 12, 24, 48 , and $96 \mathrm{~h}$.

\section{Statistical Analyses}

Although we collected arthropod data at several time points (fig. 1), we based all analyses on plant means across all sampling dates to reduce the number of zero counts and thus improve the distribution of the data with respect to the assumptions of our statistical procedures. When plants senesced during the experiment, it was necessary to base means on fewer than five arthropod censuses. All 320 plants were growing on July 14; 315 on July 25 and August 2; 299 on August 16; and 261 on August 25. At the conclusion of the experiment, 137 and 124 plants were alive in the ant-exclusion and control treatments, respectively, numbers that did not differ significantly from the expectation of equal survival for the two treatments $\left(\chi^{2}=2.89, \mathrm{df}=1, P=.09\right)$.

We performed all statistical analyses with SAS, version 9.1 (SAS Institute 2003). Our data were right skewed (i.e., many small and relatively few large counts) and overdispersed with respect to the Poisson distribution; that is, the variance exceeded the mean. Generalized linear models (e.g., SAS procedures GENMOD and GLIMMIX) provide a more powerful approach to the analysis of nonnormal 
data than transforming data and using approaches requiring a normal distribution (e.g., SAS procedures MIXED and GLM; Littell 2006). Consequently, we performed all our analyses using generalized linear mixed models with the GLIMMIX procedure. Because our data were overdispersed, we fitted them to a negative binomial distribution, which has one more parameter than the Poisson that can be used to adjust the variance independent of the mean (Littell 2006). GLIMMIX allows for a combination of fixed and random effects but currently does not offer a way to test for the significance of random effects (SAS Institute, personal communication). Consequently, we treated ant mound as a random effect and all others as fixed. Our approach thus takes advantage of the power provided by generalized linear models, especially with regard to the nonnormal distribution of our data, but it goes against the convention of treating genetic family as a random effect (Newman et al. 1997).

We tested for effects of ant exclusion, milkweed family, and ant $\times$ milkweed family interaction on Aphis, Myzocallis, and predatory arthropods. For ants, we used data only from ant-exposed plants and first tested for the effects of milkweed family alone. In order to investigate the mechanisms underlying milkweed family effects on ants, we then tested for the effects of milkweed family, with Aphis and Myzocallis abundance, milkweed family $\times$ Aphis, and milkweed family $\times$ Myzocallis as covariates. With this approach, a significant effect of milkweed family on ants in the absence but not in the presence of a significant covariate suggests that the milkweed family effect on ants is indirect and mediated by aphids. A significant aphid $\times$ milkweed family interaction shows that the number of ants recruited to milkweed per aphid differs among milkweed families. We explored the relationships among arthropod groups with genetic correlations between least squares family means obtained from these statistical models.

In order to determine the effects of our experimental manipulations on monarch caterpillars, we performed a survival analysis modeling survival as a function of ant exclusion, milkweed family, and total aphid abundance (both species combined) with the procedure LOGISTIC. Because our data were interval censused, we used the complementary log-log model (Allison 1999). We exponentiated the parameter estimates and 95\% confidence intervals and present results as probabilities. We also related caterpillar survival to ant abundance by estimating genetic correlations between milkweed family means for ant and aphid abundance at the time of the bioassay and mean family survival from the final caterpillar census.

\section{Results \\ Effects of Ants on Aphids and Predators}

Arthropod abundances and the effects of ant exclusion were relatively constant over the course of the experiment (fig. 1), supporting our decision to analyze plant means for arthropod abundances and thus ignore temporal dynamics (see "Statistical Analyses"). Comparing ant exclusion and control treatments across all milkweed genetic families showed that ants had sizable effects on the abundances of all other arthropods. Across all milkweed families, ants benefited the tended aphid Aphis: the presence of ants increased Aphis abundance by $59 \%$ compared to the exclusion treatment $(F=2.02$, df $=1,237, P=$ .0019 ; fig. $2 A$ ). In contrast, ants reduced the abundance of the untended aphid Myzocallis by 52\% ( $F=59.95$, $\mathrm{df}=1,237, P<.0001$; fig. $2 B)$. Ants reduced arthropod predator abundance by $56 \%$, from $1.5 \pm 0.1$ (mean \pm $\mathrm{SE})$ to $0.3+0.1$ predators per plant $(F=72.64$, $\mathrm{df}=$ $1,237, P<.0001)$.

\section{Interactive Effects of Ants and Milkweed Family on Aphids and Predators}

The effects of ant exclusion on Aphis depended on milkweed family (milkweed family $\times$ ant interaction: $F=$ 2.02, $\mathrm{df}=31,237, P=.0019$; fig. $2 A$ ). Ants increased Aphis abundance on 20 milkweed families but reduced Aphis abundance on the other 12 families. Separate tests for the effects of ants on Aphis on these two groups of families were both significant. On the 20 milkweed families for which effects of ants were positive, ants increased Aphis abundance from $5 \pm 1$ to $12 \pm 1$ aphids per plant, for an increase of $154 \%(F=12.26, \mathrm{df}=1,109, P=.0007)$; on the 12 milkweed families for which effects of ants were negative, ants decreased Aphis abundance from $11 \pm 1$ to $5 \pm 1$ aphids per plant, for a decrease of 53\% ( $F=$ $22.90, \mathrm{df}=1,169, P=.0001)$. Separate tests for the effect of ants on each of the 32 milkweed families showed only 12 significant or marginally significant results $(P<.10)$ because of the relatively small sample size in each test ( $N=10$ plants per family). Of these 12 milkweed families, nine showed positive effects of ants and three showed negative effects (results not shown). Consequently, milkweed family influenced not only the magnitude but also the direction of ant effects on Aphis. There was 16-fold and 18-fold variation in Aphis abundance among milkweed families in the presence and absence of ants, respectively.

In contrast to their highly variable effects on Aphis, ants consistently reduced Myzocallis abundance, although there was an indication that the strength of these negative effects differed among milkweed families (milkweed 

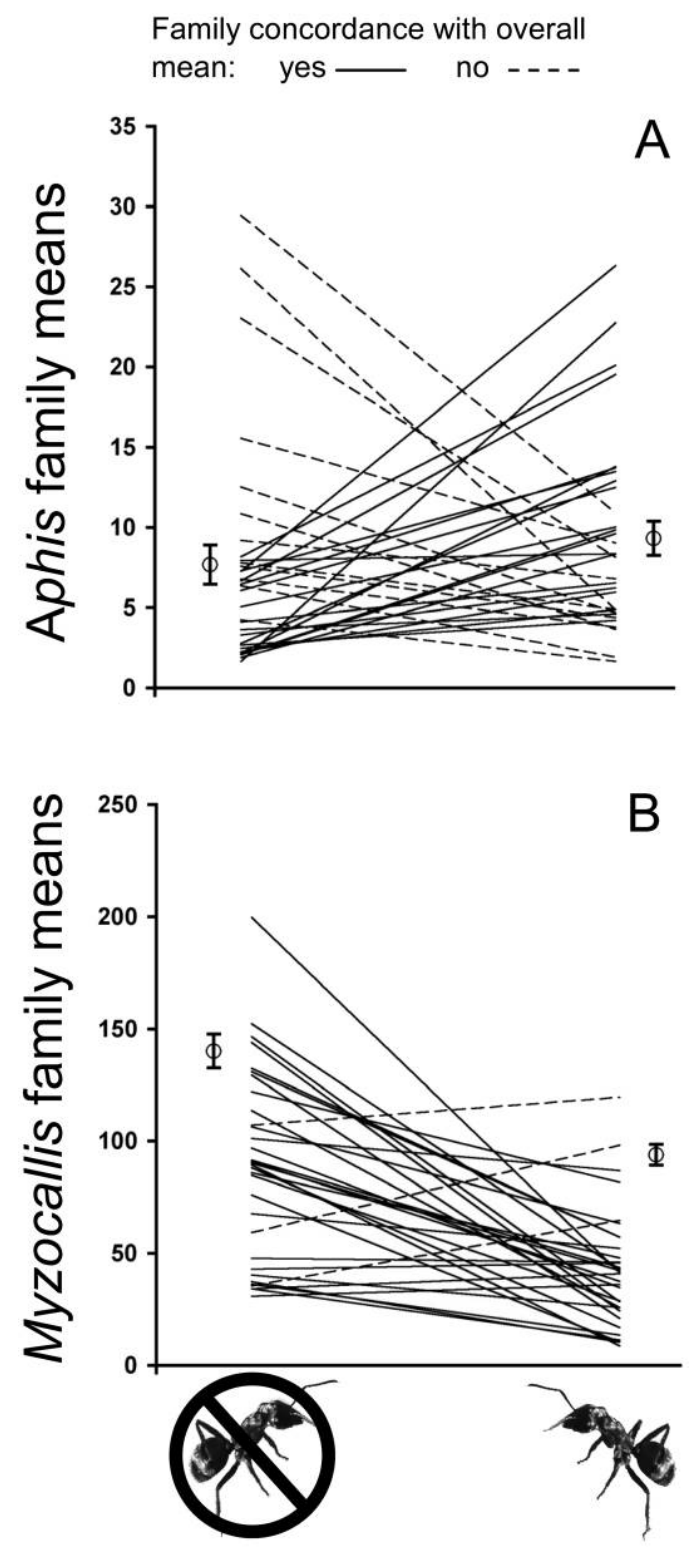

Figure 2: Effects of ants on tended Aphis asclepiadis and untended Myzocallis asclepiadis. Reaction norms for aphid abundance on milkweed families in the presence and absence of ants $(N=5$ per family). Overall means $( \pm 1 \mathrm{SE} ; N=160)$ differ significantly $(P<.05)$ and are shown beside reaction norms. Ants increased Aphis abundance and reduced Myzocallis abundance. The reaction norm slopes differed for Aphis $(P<.05)$ but not for Myzocallis $(P=.07)$. Ants increased Aphis abundance on 20 families but reduced their abundance on 12 families.

family $\times$ ant interaction: $F=1.44, \mathrm{df}=31,237, P=$ .07 ; fig. $2 B$ ). There was 10 -fold and eightfold variation in Myzocallis abundance among milkweed families in the presence and absence of ants, respectively.

While ants reduced arthropod predator abundance (see
"Effects of Ants on Aphids and Predators"), there was no detectable effect of milkweed family on arthropod predator abundance $(F=0.90, \mathrm{df}=31,237, P=.63)$. Furthermore, the effect of ants on arthropod predators did not differ among milkweed families (ant $\times$ milkweed family interaction: $F=0.44, \mathrm{df}=31,237, P=.99$ ).

\section{Indirect Effects of Milkweed Family on Ants through Interaction Chains}

On control plants, ant abundance varied 13-fold across milkweed families, and this effect was marginally significant $(F=1.45, \mathrm{df}=31,109, P=.08)$. Subsequent analyses strongly suggest that this effect of milkweed family on ants was indirect and due to the direct effects of milkweed on aphids; ant abundance was positively related to the abundance of both Aphis $(F=29.10, \mathrm{df}=1,107$, $P<.0001)$ and Myzocallis $(F=29.21, \mathrm{df}=1,107, P<$ $.0001)$, and when aphid abundance was included in the statistical model, there was no longer an indication of a milkweed family effect on ants $(F=0.71$, df $=31,107$, $P=.86)$. This result is also seen in genetic correlations: milkweed family means for ant abundance increased linearly with family means for the abundance of both tended Aphis $\left(R^{2}=0.39, F=18.78, \mathrm{df}=1,30, P=\right.$ .0002 ; fig. $3 A$ ) and, somewhat surprisingly, untended $M y$ zocallis as well $\left(R^{2}=0.21, F=7.88, \mathrm{df}=1,30, P=\right.$ .0087; fig. 3B).

Ant and Myzocallis abundance were thus positively correlated (fig. 3B) despite the fact that Myzocallis is not tended and ants reduced its abundance (fig. $2 B$ ). The association between Myzocallis and ants was not mediated by Aphis, as the abundances of the two aphid species were uncorrelated in the presence of ants $(r=0.13, N=32$, $P=.47$; fig. 4). While ants did not tend Myzocallis, we frequently observed them collecting honeydew from leaves underlying Myzocallis colonies. Supporting our observations is the fact that Myzocallis honeydew accumulated on milkweed significantly more when we excluded ants (table 1). Consequently, the presence of Myzocallis honeydew still resulted in ants recruiting to milkweed canopies, even though this aphid was never tended.

\section{Indirect Effects of Milkweed Family on Ants through Interaction Modification}

The number of ants recruited to milkweed per aphid (i.e., the slope of ant abundance regressed on aphid abundance) differed among milkweed families for both Aphis (milkweed family $\times$ ant interaction: $F=2.31, \mathrm{df}=$ $31,108, P=.0008$; fig. $3 C$ ) and Myzocallis (milkweed family $\times$ ant interaction: $F=1.76, \mathrm{df}=31,108, P=$ .0168; fig. $3 D$ ). In this way, milkweed family influenced ant 

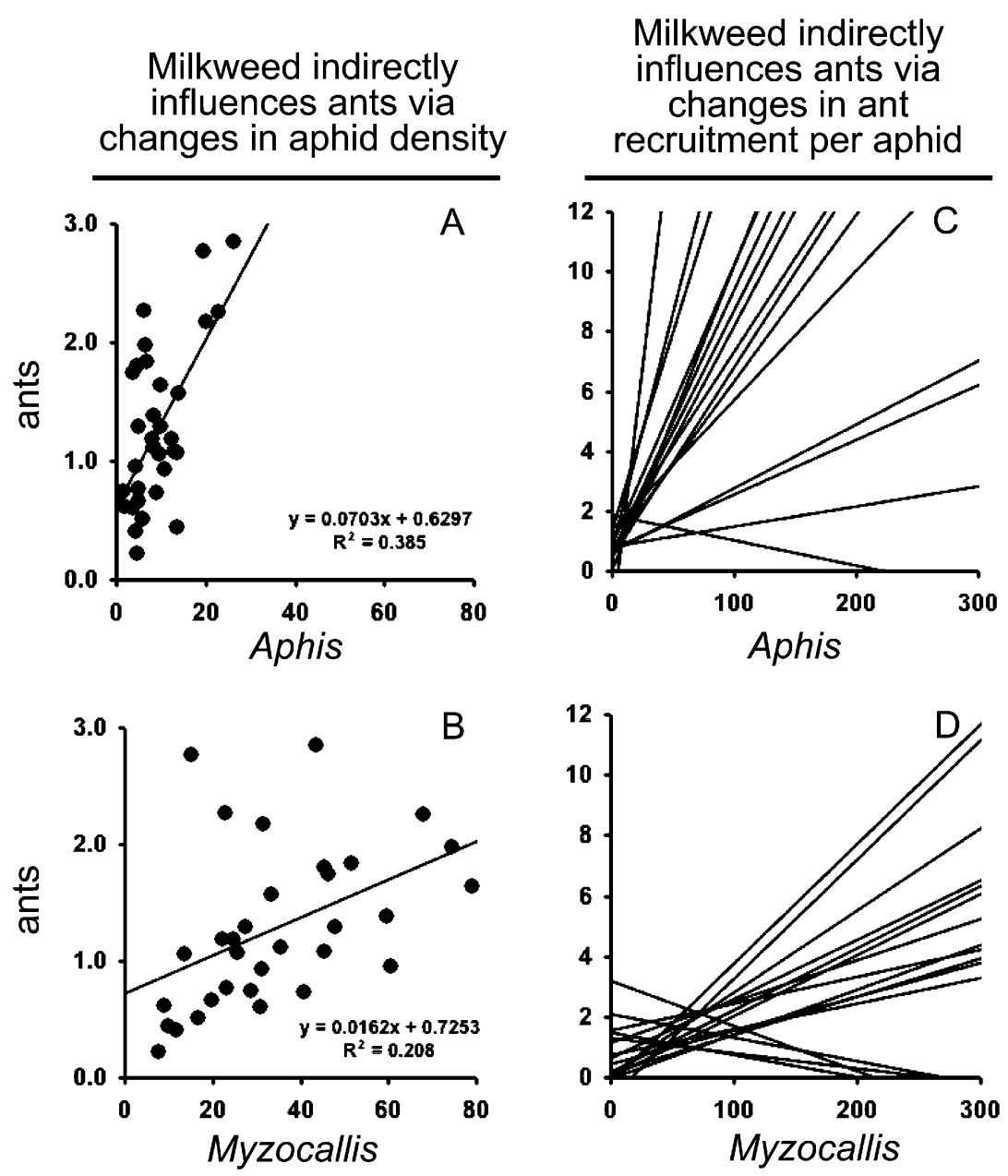

Figure 3: Mechanisms of milkweed influence over ant abundance. $A, B$, In the first mechanism, ants responded to milkweed family $(N=5$ per family) variation in aphid abundance in a density-mediated indirect interaction. $C, D$, In the second mechanism, aphid recruitment per ant (i.e., the slope of ant abundance regressed on aphid abundance) varied among milkweed families in a trait-mediated indirect interaction (for clarity, data points are not shown, and only 16 of 32 families [randomly selected] are depicted). Ant recruitment by these two mechanisms was significantly higher for ant-tended Aphis than for untended Myzocallis. Axis scales differ between $A / B$ and $C / D$ to reflect the full range of data values used in the respective analyses.

abundance not only via effects on aphid abundance (see "Indirect Effects of Milkweed Family on Ants through Interaction Chains") but also by modifying the nature of the pairwise interactions between ants and each aphid species.

\section{Evidence of Aphid-Recruited Ants as a Genetically Based Indirect Plant Defense}

Ants reduced monarch caterpillar survival from $37 \%$ to $6 \%$ $\left(\chi^{2}=49.29, \mathrm{df}=1, P<.0001\right)$. Aphid abundance was negatively associated with monarch survival, but this effect depended on whether ants were present (aphid $x$ ant interaction: $\chi^{2}=7.74, \mathrm{df}=1, P=.005$ ): without ants, there was a trend that aphid abundance was positively as- sociated with monarch survival $\left(\chi^{2}=3.11, \mathrm{df}=1, P=\right.$ .08 ); when ants were present, aphids reduced monarch survival by $11 \%$ for every 10 additional aphids $\left(\chi^{2}=19.27\right.$, $\mathrm{df}=1, P<.0001)$. Thus, aphids had a negative indirect effect on monarch survival that resulted from attraction of ants.

Milkweed family means for the probability of monarch survival ranged from $0 \%$ to $100 \%$, but there was no detectable influence of either family $\left(\chi^{2}=22.74, \mathrm{df}=31\right.$, $P=.86)$ or ant $\times$ family interaction $\left(\chi^{2}=27.86, \mathrm{df}=\right.$ $31, P=.63$ ) on survival. Nonetheless, on plants with ants, we found negative genetic correlations between aphid abundance and monarch survival $(r=-0.47, N=32$, $P=.0068)$ and between ant abundance and monarch sur- 

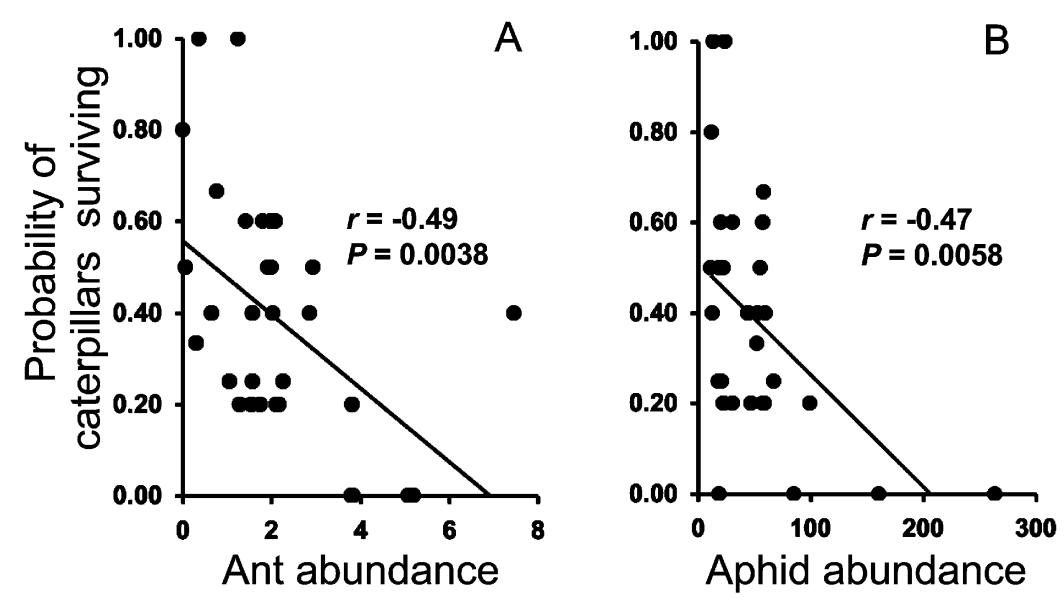

Figure 4: Effects of milkweed heritable variation in ants and aphids on monarch caterpillar survival. $A$, Milkweed family means $(N=5$ plants) for ant abundance are negatively correlated with family means for monarch caterpillar survival. $B$, Family means for aphid abundance are negatively correlated with family means for caterpillar survival in the presence of ants.

vival $(r=-0.49, N=32, P=.0038$; fig. 4$)$. At the same time, there was no genetic correlation between aphid abundance and monarch survival in the absence of ants $(r=-0.21, N=32, P=.24)$. These genetic correlations are more powerful than the overall test for a family effect on monarch survival because they directly relate quantitative variation in monarch survival to the genetically based variation in ant and aphid abundance.

The different pathways by which milkweed influenced ant abundance (fig. 3) - and thus monarch survival-were uncorrelated with each other $(r<0.13, N=32, P>.47$ in all cases; fig. 3). Selection for recruitment of ants via each aphid species might occur independently; resistance to Aphis and Myzocallis was uncorrelated in the presence of ants ( $r=0.13, N=32, P=.47)$. Nevertheless, resistance to the two aphids was positively correlated when ants were absent ( $r=0.49, N=32, P=.0037$; fig. 5). Abundance of each aphid species in the presence and absence of ants was uncorrelated for both Aphis $(r=-0.08, N=32$, $P=.65)$ and Myzocallis $(r=0.12, N=32, P=.51)$.

\section{Discussion}

\section{Plant Genetic Effects on Community Structure}

When assessing the influence of plant genotype on the structure of arthropod communities, it is informative to compare the magnitude of genotypic effects with those ecological factors traditionally considered to be of importance, such as predation, parasitism, and mutualism (Ricklefs and Miller 2000). Ants are expected to have substantial ecological impact because of their strong effects as predators of most arthropods but critical mutualists of certain sap-feeding hemipterans (Mooney 2006, 2007; Styrsky and Eubanks 2007). Nevertheless, our exclusion of ants had relatively modest effects, increasing (Aphis) or decreasing (Myzocallis, predators) arthropod abundance by between $52 \%$ and $59 \%$. In contrast, we found much stronger effects of genetically based variation among full-sib families of milkweed.

Aphid abundance varied between eight- and 18-fold among milkweed families, depending on aphid species and whether ants were present. In the case of Aphis, even the direction of ant effects-that is, whether ant-Aphis interactions were mutualistic or antagonistic-depended on milkweed family. In addition, the greatest mutualistic and antagonistic effects mediated by plant genotypes were of the same magnitude (i.e., slope magnitudes in fig. $2 \mathrm{~A}$ ). As a consequence of these direct genetic effects on aphids, there was 13-fold variation in ant abundance. These results show the importance of context dependence in ecological interactions (Bronstein 1994) and underscore the novel aspect of genetically based variation in resources as an important factor structuring interspecific interactions. Our bioassay further showed that variation among milkweed

Table 1: Evidence that ants collect Myzocallis asclepiadis honeydew from leaves underneath aphid colonies

\begin{tabular}{lcc}
\hline & \multicolumn{2}{c}{$\begin{array}{c}\text { Accumulated honeydew beneath } \\
\text { Myzocallis colonies? }\end{array}$} \\
\cline { 2 - 3 } & Yes & No \\
\hline Ants present & $17(15 \%)$ & $90(85 \%)$ \\
Ants excluded & $104(89 \%)$ & $13(11 \%)$ \\
\hline
\end{tabular}

Note: $\chi^{2}=120.0, \mathrm{df}=1, P<.0001$. Values are number of leaves, with leaf percentage in parentheses. 


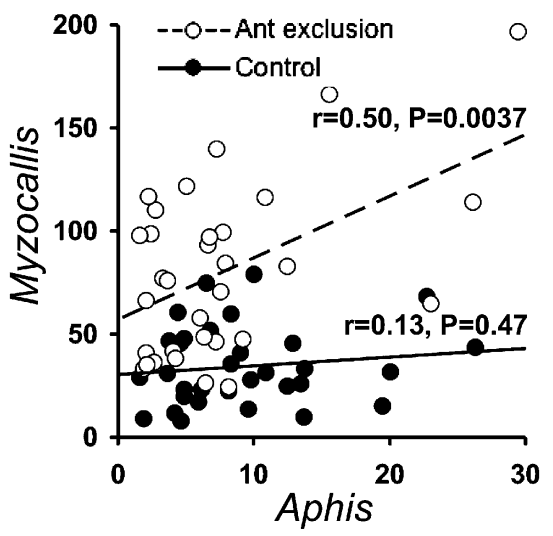

Figure 5: Milkweed resistance to ant-tended Aphis and untended $M y$ zocallis in the presence and absence of ants. Milkweed family means $(N=5$ per family) for the two aphids are uncorrelated in the presence of ants but correlated in their absence.

families was negatively correlated with monarch caterpillar survival, which ranged from $0 \%$ to $100 \%$ among milkweed families. In contrast to these large genetic effects, our previous work on the consequences of induced milkweed defensive traits for community structure found more modest consequences (Van Zandt and Agrawal 2004a, 2004b). Johnson and colleagues reached similar conclusions, showing that genetic variation in evening primrose Oenothera biennis L. had much larger effects on arthropod communities than did ants or other ecological factors (Johnson and Agrawal 2005; McGuire and Johnson 2006; Johnson 2008). Consequently, evidence is mounting that plant genetic effects on community structure are as strong as or stronger than those of interspecific interactions (Johnson and Agrawal 2005).

We document several means by which milkweed family determined arthropod community structure. Milkweed family indirectly influenced ants because ant abundance increased linearly with aphid abundance (i.e., an interaction chain; fig. 3A, 3B; Breton and Addicott 1992). Our novel result is that milkweed family also influenced the per aphid rate of ant recruitment (i.e., an interaction modification; fig. 3C, 3D). Wimp and Whitham (2001) demonstrated the influence of hybrid and parental plant genotypes on ants arising from direct effects on aphid abundance. Our results build on theirs by demonstrating that plant genetics modified the nature of the pairwise interaction between ants and two aphid species and revealing the lack of genetic correlations among the various ecological pathways by which plants affected ants.

We have also shown that the indirect effects of plant genetics on ants are not restricted to effects transmitted via ant-hemipteran mutualisms. Although ants reduced the abundance of untended Myzocallis, milkweed family effects on Myzocallis abundance nevertheless resulted in strong indirect effects on ants. This was due to the fact that Formica podzolica collected honeydew from underneath untended Myzocallis aphid colonies (table 1). The attraction of ants to this source of honeydew demonstrates that untended aphids may recruit ants, which in turn can have strong effects on canopy arthropod communities. Consequently, the plant-based collection of honeydew represents an important indirect link between untended aphids and the other arthropods with which ants interact. This and other forms of plant-based honeydew collection appear to be common (Davidson et al. 2003). That heritable plant variation modulates such complex multispecies interactions via both tended and untended hemipterans indicates that many plants lacking ant-aphid mutualisms, or obvious morphological features to attract ants, may still exert a strong, albeit cryptic, influence over predaceous ant abundance.

\section{Mechanisms of Plant-Mediated Effects on Aphids and Ants}

Elucidating the mechanisms of milkweed genetic influence over arthropod communities is beyond the goals of this study, but we speculate that variation in the constitution of phloem sap plays a role. Assuming that variation in phloem sap is genetically based, this could then translate into different honeydew compositions for aphids on different plant genotypes. Ultimately, if ants can detect and respond to these differences, then phloem sap may be mediating specific plant genotype-ant interactions. Indeed, it is known that ant recruitment depends strongly on the quality and quantity of hemipteran honeydew (Volkl et al. 1999). There is some evidence that plant quality can affect ant tending of mutualist insects (reviewed in Morales and Beal 2006), with the strongest evidence coming from ant-lycaenid systems, in which ants increase their tending of caterpillars reared on high-quality host plants (e.g., Baylis and Pierce 1991). Although honeydew composition has been shown to vary among feeding locations within plants (Merritt 1996) and among closely related host plant species (Fischer and Shingleton 2001), we are not aware of studies that have documented a plant genetic contribution to variation in honeydew. The milkweed families used in our experiment showed significant heritabilities for six traits (see "Methods"), none of which correlated with the effects we observed on aphids and ants (data not shown). Nevertheless, our data indicate that the genetic families used here varied in some unmeasured trait, possibly phloem sap constitution, that modulated the interactions. Vrieling et al. (1991) similarly hypothesized that variation in pyrrolizidine alkaloids in the phloem of $S e$ necio jacobaea altered ant-aphid interactions. 


\section{Top-Down Effects of Heritable Community Structure}

Just as plant genotype can influence community structure, so too can community structure feed back to affect plant fitness and evolution (Whitham et al. 2006; Johnson and Stinchcombe 2007). Although we did not measure components of plant fitness, we investigated whether aphidrecruited ants might serve as a genetically based indirect defense for milkweed against other herbivores, such as monarch caterpillars. For such dynamics to occur, three criteria must be met: first, plants must exert indirect, genetically based control over ants; second, these ants must be capable of reducing the abundance of herbivores that affect plant fitness; and third, heritable variation in ant abundance must contribute to variation in herbivore survival. We document several means by which milkweed exerted genetic influence over ant abundance (fig. 3), satisfying criterion 1 . Our bioassay documented that aphidrecruited ants not only fed on honeydew but also reduced monarch caterpillar survival by two-thirds, thus satisfying criterion 2. While we did not show that monarch caterpillars reduced milkweed fitness, past work on milkweed's foliage-chewing herbivores suggests that this is possible (Agrawal 2004, 2005). There are various forms of evidence that satisfy criterion 3. Although we did not detect an effect of milkweed family on monarch survival, the negative genetic correlation between ant abundance and monarch survival (fig. 4) demonstrates that genetically based variation in ant recruitment in turn leads to genetically based variation in indirect defense of milkweed by those ants.

It has long been hypothesized that ant-attracting hemipterans may benefit plants through their consumption or deterrence of other damaging herbivores (Way 1963; Messina 1981; Floate and Whitham 1994; Mooney and Tillberg 2005). On milkweeds, ants frequently roam among plant leaves between honeydew feeding bouts (K. A. Mooney and A. A. Agrawal, personal observations), making chance encounters with monarch caterpillars and other milkweed herbivores likely. A separate study at this site has shown that the principal benefit of ants to Aphis is the removal of competing herbivores (Smith et al., forthcoming), suggesting that predation of untended herbivores may be an important component of this ant-aphid interaction. Furthermore, honeydew is rich in carbohydrates and can thus create dietary imbalances that increase the carnivorous tendencies of ants (Offenberg 2001). These dynamics are also not limited to milkweed; evidence from a wide variety of communities shows that hemipterantending ants remove untended herbivores (Styrsky and Eubanks 2007).

Recruiting ants with aphids presents a potential conflict of interest from the plant's perspective; although lowered resistance to aphids brings ants to plants, this comes at the cost of herbivory by those aphids. This trade-off between ant attendance and aphid herbivory is due to two forms of costs. First, the benefits of ant attendance trade off against the cost of herbivory by the aphids that attracted those ants. Styrsky and Eubanks (2007) found that hemipteran-tending ants most often (22 of 30 studies reviewed) have net negative effects on total herbivore abundance. Likewise, Mooney and Tillberg (2005) found that the diet of F. podzolica on pines in Colorado included substantial quantities of both honeydew and arthropod prey. This suggests that the costs to plants of increases in ant abundance via aphids may be offset by the benefits to plants of having predaceous ants as regular visitors to their canopies. Furthermore, we found milkweed genetic variation for ant recruitment on a per aphid basis that, at least in part, uncouples aphid abundance from ant recruitment (fig. 3C, 3D). Second, plant genotypes that benefit from attendance by aphid-attracted ants may suffer high costs of herbivory when ants are absent. Surprisingly, we found no genetic correlations between aphid abundance in the presence and absence of ants for either aphid species. In other words, some plant genotypes were resistant to aphids in the absence of ants but supported higher densities of aphids in the presence of ants. In addition, because ant recruitments via Aphis and Myzocallis were uncorrelated (fig. 5), any selection to increase ant abundance on milkweed could act independently via each aphid species. At the same time, milkweed employed correlated resistance against those same herbivores when ants were absent. The costs of aphid herbivory associated with ant attendance can thus be partially circumvented, and these costs may be low compared to the benefits of ant protection.

Whether plant genetic effects shape community structure through interaction chains or through interaction modification has important implications for whether community structure will feed back as a source of selection on plant traits. If plant genetic effects operate entirely through interaction chains (e.g., fig. $3 A, 3 B$ ), then arthropod species under indirect genetic control may alter plant fitness, but they cannot select on plant traits (Inouye and Stinchcombe 2001; Strauss et al. 2005). For example, if a plant influenced ants only through variation in aphid abundance (e.g., Wimp and Whitham 2001), ants might increase plant fitness by removing aphids, but selection on plant traits would remain unchanged by ants. In contrast, if plant genetic effects operated via interaction modification (e.g., fig. $3 C, 3 D$ ), then selection on plant traits could come from indirect interactions. In this study, ants might select on those heritable plant traits that determine the rate of ant recruitment to aphids, such as the quality or quantity of phloem sap. Consequently, whether plant genetic effects act via interaction chains or interaction modification determines whether trait evolution in plants is 
driven entirely by the pairwise plant-herbivore interaction, as is traditionally envisioned by evolutionary ecologists, or whether a consideration of genetically based variation in community structure contributes to such evolutionary dynamics.

\section{Conclusions}

The dynamics we have observed here are likely broadly applicable to this community; milkweed populations are consistently genetically diverse (Agrawal 2004, 2005; Smith et al., unpublished data) and ants are abundant in many old-field communities (K. A. Mooney and A. A. Agrawal, personal observations). In addition, the rate of ant recruitment to Aphis and Myzocallis varied among milkweed families in another experiment conducted at this same site in 2006 (K. A. Mooney and A. A. Agrawal, unpublished data). More generally, this experiment contributes to a growing body of evidence for the importance of plant genotype in structuring arthropod communities (Maddox and Root 1990; Johnson and Agrawal 2005; Crutsinger et al. 2006; Whitham et al. 2006), and this is now one of three studies showing that the abundance of aphid-tending ants varies among plant genotypes (Wimp and Whitham 2001; Johnson 2008). Our work also confirms the emerging pattern that ants that promote the abundance of tended herbivores simultaneously reduce the abundance of other untended herbivores (Styrsky and Eubanks 2007). The novel findings of our study are that plant genotype can shape community structure by modifying the interactions among resident arthropods, and, through these complex dynamics, honeydew-collecting ants can constitute a genetically based indirect plant defense.

\section{Acknowledgments}

This work was funded by National Science Foundation grant DEB-0447550, the Biogeochemistry and Biocomplexity Initiative at Cornell University, and the University of California, Irvine, School of Biological Sciences. We thank P. Jones for assistance in the field and lab and L. Fox, M. Johnson, A. Kessler, J. Lau, J. Parker, M. Stastny, J. Thaler, and anonymous reviewers for comments on the manuscript.

\section{Literature Cited}

Abrams, P. A. 1995. Implications of dynamically variable traits for identifying, classifying, and measuring direct and indirect effects in ecological communities. American Naturalist 146:112-134.

Agrawal, A. A. 2004. Resistance and susceptibility of milkweed to herbivore attack: consequences of competition, root herbivory, and plant genetic variation. Ecology 85:2118-2133.

2005. Natural selection on common milkweed (Asclepias syriaca) by a community of specialized insect herbivores. Evolutionary Ecology Research 7:651-667.

Allison, P. D. 1999. Logistic regression using the SAS system: theory and application. SAS Institute, Cary, NC.

Baylis, M., and N. E. Pierce. 1991. The effect of host-plant quality on the survival of larvae and oviposition by adults of an anttended lycaenid butterfly, Jalmenus evagoras. Ecological Entomology 16:1-9.

Breton, L. M., and J. F. Addicott. 1992. Density-dependent mutualism in an aphid-ant interaction. Ecology 73:2175-2180.

Bronstein, J. L. 1994. Conditional outcomes in mutualistic interactions. Trends in Ecology \& Evolution 9:214-217.

Crutsinger, G. M., M. D. Collins, J. A. Fordyce, Z. Gompert, C. C. Nice, and N. J. Sanders. 2006. Plant genotypic diversity predicts community structure and governs an ecosystem process. $\underline{\text { Science }}$ 313:966-968

Davidson, D. W., S. C. Cook, R. R. Snelling, and T. H. Chua. 2003. Explaining the abundance of ants in lowland tropical rainforest canopies. Science 300:969-972.

Fischer, M. K., and A. W. Shingleton. 2001. Host plant and ants influence the honeydew sugar composition of aphids. Functional Ecology 15:544-550.

Floate, K. D., and T. G. Whitham. 1994. Aphid-ant interaction reduces chrysomelid herbivory in a cottonwood hybrid zone. Oecologia (Berlin) 97:215-221.

Fritz, R. S., and E. L. Simms. 1992. Plant resistance to herbivores and pathogens: ecology, evolution, and genetics. University of Chicago Press, Chicago.

Gold, J. J., and J. S. Shore. 1995. Multiple paternity in Asclepias syriaca using a paired-fruit analysis. Canadian Journal of Botany 73:12121216.

Inouye, B., and J. R. Stinchcombe. 2001. Relationships between ecological interaction modifications and diffuse coevolution: similarities, differences, and causal links. Oikos 95:353-360.

Iwao, K., and M. D. Rausher. 1997. Evolution of plant resistance to multiple herbivores: quantifying diffuse coevolution. American Naturalist 149:316-335.

Johnson, M. T. J. 2008. Bottom-up effects of plant genotype on aphids, ants and predators. Ecology 89:145-154.

Johnson, M. T. J., and A. A. Agrawal. 2005. Plant genotype and environment interact to shape a diverse arthropod community on evening primrose (Oenothera biennis). Ecology 86:874-885.

Johnson, M. T. J., and J. R. Stinchcombe. 2007. An emerging synthesis between community ecology and evolutionary biology. Trends in Ecology \& Evolution 22:250-257.

Littell, R. C. 2006. SAS for mixed models. SAS Institute, Cary, NC. Maddox, G. D., and R. B. Root. 1990. Structure of the encounter between goldenrod (Solidago altissima) and its diverse insect fauna. Ecology 71:2115-2124.

Madritch, M., J. R. Donaldson, and R. L. Lindroth. 2006. Genetic identity of Populus tremuloides litter influences decomposition and nutrient release in a mixed forest stand. Ecosystems 9:528-537.

McGuire, R. J., and M. T. J. Johnson. 2006. Plant genotype and induced responses affect resistance to herbivores on evening primrose (Oenothera biennis). Ecological Entomology 31:20-31.

Merritt, S. Z. 1996. Within-plant variation in concentrations of amino acids, sugar, and sinigrin in phloem sap of black mustard, Brassica nigra (L.) Koch (Cruciferae). Journal of Chemical Ecology 22:1133-1145.

Messina, F. J. 1981. Plant-protection as a consequence of an ant- 
membracid mutualism: interactions on goldenrod (Solidago sp.). Ecology 62:1433-1440.

Mooney, K. A. 2006. The disruption of an ant-aphid mutualism increases the effects of birds on pine herbivores. Ecology 87:18051815.

2007. Tritrophic effects of birds and ants on a canopy food web, tree growth and phytochemistry. Ecology 88:2005-2014.

Mooney, K. A., and C. V. Tillberg. 2005. Temporal and spatial variation to ant omnivory in pine forests. Ecology 86:1225-1235.

Morales, M. A., and A. L. H. Beal. 2006. Effects of host plant quality and ant tending for treehopper Publilia concava. Annals of the Entomological Society of America 99:545-552.

Newman, J. A., J. Bergelson, and A. Grafen. 1997. Blocking factors and hypothesis tests in ecology: is your statistics text wrong? Ecology 78:1312-1320.

Offenberg, J. 2001. Balancing between mutualism and exploitation: the symbiotic interaction between Lasius ants and aphids. Behavioral Ecology and Sociobiology 49:304-310.

Peacor, S. D., and E. E. Werner. 2001. The contribution of traitmediated indirect effects to the net effects of a predator. Proceedings of the National Academy of Sciences of the USA 98:39043908.

Preisser, E. L., D. I. Bolnick, and M. F. Benard. 2005. Scared to death? the effects of intimidation and consumption in predator-prey interactions. Ecology 86:501-509.

Rausher, M. D. 1992. The measurement of selection on quantitative traits: biases due to environmental covariances between traits and fitness. Evolution 46:616-626.

Ricklefs, R. E., and G. L. Miller. 2000. Ecology. W. H. Freeman, New York.

Rudgers, J. A. 2004. Enemies of herbivores can shape plant traits: selection in a facultative ant-plant mutualism. Ecology 85:192205.

SAS Institute. 2003. SAS, version 9.1. SAS Institute, Cary, NC.

Smith, R. A., K. A. Mooney, and A. A. Agrawal. Forthcoming. Coexistence of three specialist aphids on common milkweed Asclepias syriaca. Ecology.
Strauss, S. Y., H. Sahli, and J. K. Conner. 2005. Toward a more traitcentered approach to diffuse (co)evolution. New Phytologist 165: $81-89$.

Styrsky, J. D., and M. D. Eubanks. 2007. Ecological consequences of interactions between ants and honeydew-producing insects. Proceedings of the Roval Society B: Biological Sciences 274:151-164.

Van Zandt, P. A., and A. A. Agrawal. 2004a. Community-wide impacts of herbivore-induced plant responses in milkweed (Asclepias syriaca). Ecology 85:2616-2629.

2004b. Specificity of induced plant responses to specialist herbivores of the common milkweed, Asclepias syriaca. Oikos 104: 401-409.

Volkl, W., J. Woodring, M. Fischer, M. W. Lorenz, and K. H. Hoffmann. 1999. Ant-aphid mutualisms: the impact of honeydew production and honeydew sugar composition on ant preferences. Oecologia (Berlin) 118:483-491.

Vrieling, K., W. Smit, and E. Van der Meijden. 1991. Tritrophic interactions between aphids (Aphis jacobaeae Schrank), ant species, Tyria jacobaeae L., and Senecio jacobaea L. lead to maintenance of genetic variation in pyrrolizidine alkaloid concentration. Oecologia (Berlin) 86:177-182.

Way, M. J. 1963. Mutualism between ants and honeydew-producing Homoptera. Annual Review of Entomology 8:307-344.

Whitham, T. G., J. K. Bailey, J. A. Schweitzer, S. M. Shuster, R. K. Bangert, C. J. Leroy, E. V. Lonsdorf, et al. 2006. A framework for community and ecosystem genetics: from genes to ecosystems. Nature Reviews Genetics 7:510-523.

Wimp, G. M., and T. G. Whitham. 2001. Biodiversity consequences of predation and host plant hybridization on an aphid-ant mutualism. Ecology 82:440-452.

Wootton, J. T. 1994. The nature and consequences of indirect effects in ecological communities. Annual Review of Ecology and Systematics 25:443-466.
Associate Editor: Judith L. Bronstein Editor: Michael C. Whitlock 